\title{
Correction to: Dorsal Column Stimulation and Cannabinoids in the Treatment of Chronic Nociceptive and Neuropathic Pain: a Review of the Clinical and Pre-clinical Data
}

\author{
Charles A. Odonkor ${ }^{1}$ D $\cdot$ Tariq AlFarra $^{2} \cdot$ Peju Adekoya ${ }^{3} \cdot$ Vwaire Orhurhu $^{4} \cdot$ Tomás Rodríguez $^{5} \cdot$ Emily Sottosanti $^{6}$. \\ Alan D. Kaye ${ }^{7}$
}

Published online: 15 February 2022

(c) The Author(s), under exclusive licence to Springer Science+Business Media, LLC, part of Springer Nature 2022

\section{Correction to: Current Pain and Headache Reports https://doi.org/10.1007/s11916-022-01008-y}

The article "Dorsal Column Stimulation and Cannabinoids in the Treatment of Chronic Nociceptive and Neuropathic Pain: a Review of the Clinical and Pre-clinical Data" was originally published electronically on the publisher's internet portal on 2 February 2022 with error on the second author name. It should be 'Tariq AlFarra' instead of 'Tariq Alfara'.
The original article has been corrected.

Publisher's Note Springer Nature remains neutral with regard to jurisdictional claims in published maps and institutional affiliations.

The original article can be found online at https://doi.org/10.1007/

s11916-022-01008-y.

Charles A. Odonkor

charles.odonkor@yale.edu

1 Department of Orthopaedics and Rehabilitation, Division of Physiatry, Interventional Pain Medicine, Yale University School of Medicine, New Haven, CT, USA

2 Department of Physical Medicine and Rehabilitation, Johns Hopkins University School of Medicine, Baltimore, MD, USA

3 Department of Anesthesia and Critical Care, Division of Pain Medicine, Johns Hopkins University School of Medicine, Baltimore, MD, USA

4 Department of Anesthesia, Critical Care and Pain Medicine, Division of Pain, Massachusetts General Hospital, Harvard Medical School, Boston, MA, USA

5 Therapeutics Institute, University of Massachusetts Medical School, Worcester, MA, USA

6 Department of Anesthesiology, Beth Israel Deaconess Medical Center, Critical Care and Pain, Harvard Medical School, Boston, MA, USA

7 Department of Anesthesiology, Louisiana State University Health Sciences Center, Shreveport, LA, USA 